\title{
Analysis of Thermal Effects of Roof Material on Indoor Temperature and Thermal Comfort
}

\author{
Remon Lapisa ${ }^{\mathrm{a}, 1}$, Arwizet $\mathrm{K}^{\mathrm{a}, 2}$, Martias ${ }^{\mathrm{a}, 3}$, Purwantono ${ }^{\mathrm{a}, 4}$, Wakhinuddin ${ }^{\mathrm{a}, 5}$, Suparno ${ }^{\mathrm{a}, 6}$, Zaid Romani ${ }^{\mathrm{b}}$ \\ ${ }^{a}$ Faculty of Engineering, Universitas Negeri Padang, Padang, 25132, Indonesia \\ E-mail: ${ }^{1}$ remonlapisa@ft.unp.ac.id, ${ }^{2}$ arwizet@yahoo.com, ${ }^{3}$ martias@ft.unp.ac.id, ${ }^{4}$ purwantonomsn@gmail.com, \\ 5wakhid_nuddin@yahoo.com, ${ }^{6}$ suparno121251@gmail.com \\ ${ }^{b}$ Ecole National d'Architecture Tetouan, Tetouan, 93040, Morocco \\ E-mail: romani.zaid@gmail.com
}

\begin{abstract}
The indoor thermal comfort is one of the key factors in designing an energy-efficient sustainable building. In the tropics, ensuring indoor thermal comfort using air conditioning systems is the primary cause of the high energy consumption of buildings. This thermal comfort is greatly affected by the characteristics of the building envelope material, including the roof. Zinc roofing sheet is the most common roofing material used in Indonesia because of its lightweight and easy installation. However, it is corrosive, and it has a high thermal conductivity that can lead to overheating in the room. In order to improve indoor thermal comfort, it is necessary to find alternative, environmentally friendly building roofing materials. The purpose of this experimental study is to analyze and evaluate the effect of the type of roofing material on rooms' temperature profile and indoor thermal comfort level. Temperature measurements are carried out for three consecutive days on three prototype buildings with the one-twenty scale with different roofing materials: zinc plate, bamboo, and sugar palm fiber called Ijuk. In each building, four temperature sensors connected to a temperature data logger are placed at the rooftop surface, attic zone, bedroom, and living room. The measurement results show that the type of roofing material has a significant impact on the indoor temperature profile and comfort level both day and night. Considering the thermal performance shown by the results of the study, Ijuk can be a rational choice as a roofing material for residential houses in tropical climates.
\end{abstract}

Keywords — roof material; indoor temperature; thermal comfort; tropical region.

\section{INTRODUCTION}

The thermal comfort is one of the main requirements in building design. A thermally comfortable room will affect the health and productivity of residents [1], [2]. The thermal comfort of a building is strictly related to the room temperature and humidity, and the air distribution pattern in the room [3], [4]. To ensure thermal comfort, especially in tropical regions, buildings are usually equipped with an active air conditioning system. However, the use of air conditioners to increase the thermal comfort has several disadvantages; high electrical energy consumption, air pollution, high costs of investment and maintenance, and additional space for the installation of equipment. In tropical climates such as the city of Padang-Indonesia $\left(0^{\circ} 56^{\prime} 57.3^{\prime \prime} \mathrm{N}\right.$, $100^{\circ} 21^{\prime} 15.34 "$ E) with high temperature and humidity, the consumption of electrical energy for air conditioning systems in the residential sector is relatively high at $17 \%$ of the total building consumption [5].
Thermal comfort in buildings is affected by several factors, including weather conditions, thermal characteristics of building envelope materials, internal gain, occupancy patterns, etc. [6]. To improve thermal comfort without consuming excessive energy, a bioclimatic design that pays close attention to the local climatic conditions of the building location is necessary [7]. In hot regions, one of the strategies in bioclimatic building concepts is passive cooling techniques. The use of passive cooling techniques to reduce building energy consumption in the tropics is a promising alternative solution. In an energy-efficient bioclimatic design, increasing the thermal performance of the building envelope is important. An essential part of the building envelope in the buildings' thermal performance is the roof. A study has shown that the excessive solar heat gain transferred through the roof into inside the building is one of the main causes of building thermal discomfort in the warm-humid climatic area [8].

The roof is the most affected part of the building envelope by weather changes due to direct exposure to the outside air. 
It is directly exposed to the solar [9] and thermal radiation of other surrounding objects and undergoes convection heat transfer due to the wind and rain, etc. Therefore, the selection of roofing material that is suitable for microweather conditions is a crucial research object. The materials selected for the roof must meet several requirements: structural strength aspects facing the external forces (wind, rain), economic aspects, aesthetic aspects, and thermal aspects.

In the thermal aspect, a high-performance roof must be able to reduce excessive heat radiation absorption on the surface and minimize the conduction of heat penetration into the room. Reducing the heat radiation absorption can be performed by increasing the value of the surface's albedo with a reflective coating [10] and choosing a material with a high emissivity value [11]. Minimizing heat penetration to increase thermal resistance can be done by adding thermal insulation [12], [13]. Several studies of heat transfer on the roof of a residential house show that the type of roof is very influential in reducing the heat penetration into the room [14]. Besides, several other aspects affect thermal performance in the room as in previous studies such as geometry, ventilation, the effect of inertia and internal gain, thermal stratification, the effect of the skylight on lighting and thermal comfort, and multi criterion optimization on other building envelopes [15]-[22].

This experimental study is the development of previous studies intended to analyze the effect of various types of roofing material on the room temperature and the thermal comfort of buildings. Temperature measurements are performed on three residential houses prototypes with different roofing materials. Detail descriptions of research objects and experimental protocols are presented in the material and method section. The measurement results will be presented and analyzed in the result and discussion section.

\section{MATERIAL AND METHOD}

\section{A. Description of Studied Building}

This experimental study is carried out on three prototype residential houses with different roofing materials; (a) zinc, (b) bamboo, and (c) sugar palm fiber, called ijuk. The building prototypes are rectangular with a size of $60.5 \mathrm{~cm} \times$ $32 \mathrm{~cm} \times 16 \mathrm{~cm}$ (Fig.1). These reduced size prototypes with a scale of 1:20 are representations of residential houses commonly found in Indonesia. The building walls are made of Glass-fiber Reinforced Cement Board (GRC Board) 8 $\mathrm{mm}$ thick depicting the characteristics of brick-wall with the same reduction scale. The floor is ceramic as common floor materials in residential buildings in Indonesia. The house consists of four bedrooms, one living room, one kitchen, and one toilet. The building has no occupants, lighting and cooling system, and other electronic equipment so that freefloating temperature will vary depending on the changes in environment air conditions. On the front and back facade of the building and the entire wall of the room have several permanently installed single glass windows for natural lighting sources, and cannot be opened and closed. The internal door is made of wood and left open to maximize air circulation between the rooms. The inner surface of the vertical wall is painted the same color as its outer surface. In this study, the albedo coefficient of the vertical wall is considered to be 0.4 . The detailed repartition of interior zones and room sizes are presented in Table I, and the geometry of prototype buildings are presented in Fig.1.

TABLE I

BUILDING INTERIOR ZONE REPARTITION AND ITS DIMENSIONS

\begin{tabular}{|c|l|c|}
\hline No & \multicolumn{1}{|c|}{ Zone } & Dimension \\
\hline 1 & Bed Room-1 & $12.5 \mathrm{~cm} \times 13.5 \mathrm{~cm}$ \\
\hline 2 & Bed Room-2 & $12.5 \mathrm{~cm} \times 13.5 \mathrm{~cm}$ \\
\hline 3 & Bed Room-3 & $13.0 \mathrm{~cm} \times 13.5 \mathrm{~cm}$ \\
\hline 4 & Bed Room-4 & $16.3 \mathrm{~cm} \times 13.5 \mathrm{~cm}$ \\
\hline 5 & Living Room & $31.2 \mathrm{~cm} \times 18.5 \mathrm{~cm}$ \\
\hline 6 & Kitchen & $39.3 \mathrm{~cm} \times 18.5 \mathrm{~cm}$ \\
\hline 7 & Toilet & $7.0 \mathrm{~cm} \times 9.0 \mathrm{~cm}$ \\
\hline
\end{tabular}

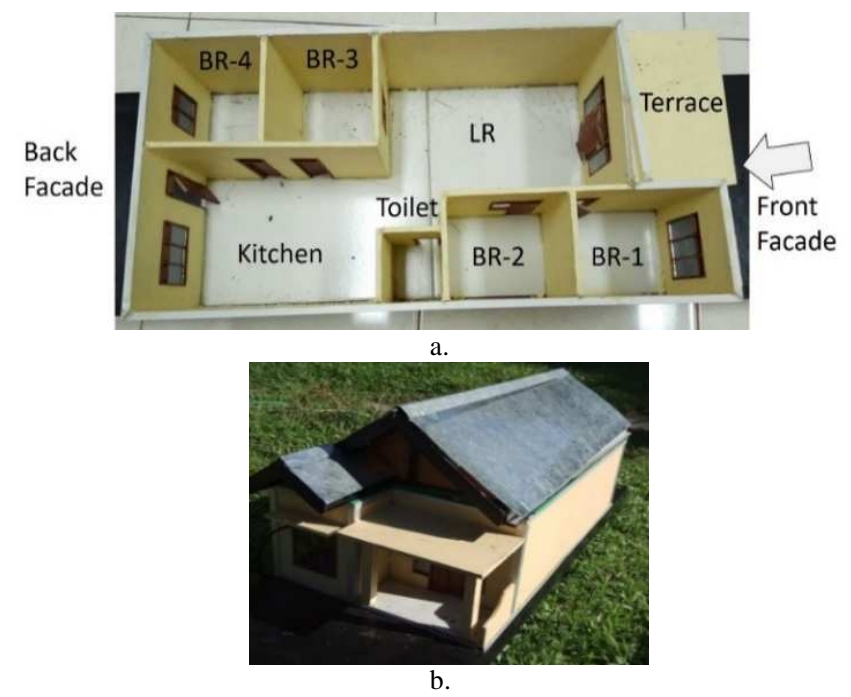

Fig. 1 a. The building prototype interior zonation, $b$. The building geometry in $3-\mathrm{D}$

\section{B. Roof Materials}

This study will analyze the effect of the roofing material on the temperature profile in the room. The three types of roofing materials compared are (1) zinc plate, (2) bamboo, and (3) Ijuk (Fig.3). The first material, zinc plated, is a material that is often found in traditional residential homes in Indonesia because of its lightweight, easy installation and maintenance, etc. However, it is corrosive, and it has a high thermal conductivity that can lead to overheating in the room.

The second material, bamboo (Figure 2a), is a grass-type plant with cavities and the internodes of the stem are widely used in the construction sector [23], [24]. Many different variants of this plant can be found easily in all regions of Indonesia. Figure $2 b$ shows an example of a residential house using bamboo as its roof. The last materials, ijuk (Fig.2.c), are a natural fiber material in the form of black fibers as the protection of the palm leaf midrib (Arenga Pinnata). In Indonesia, palm trees often grow in areas with altitudes between 400 to 1000 meters above sea level [25]. Some benefits of using ijuk include long-lasting and resistant to acids and salts [26]. Ijuk is one of the most common 
roofing materials applied in some of the traditional Indonesian houses (Fig.2.d).

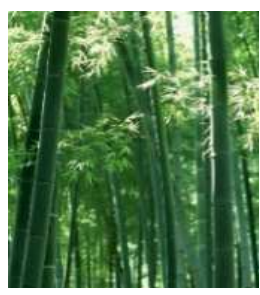

a.

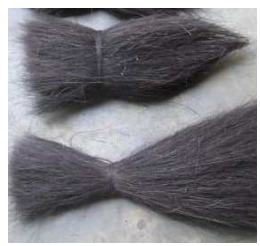

c.

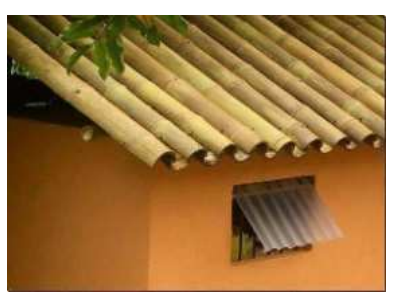

b.

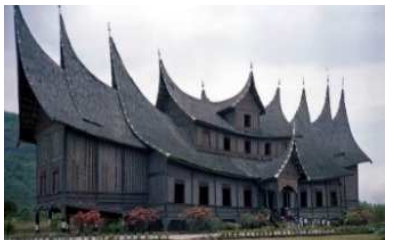

d.

Fig. 2 a. Bamboo tree, b. Houses with bamboo roofs (http://rumahpantura.com/), c. Fibres from Arenga pinnata's tree (ijuk), d. Indonesian traditional house with ijuk roof.

The roofs in each prototype are in the shape of a saddle with a tilt angle of $15^{\circ}$ (Fig.3). On the first prototype, the 1 $\mathrm{mm}$ thick zinc roof without a coating is installed directly on the roof frame (Fig.3.a). On the second one, bamboo is installed on the roof longitudinally along the sloping side. Bamboo stems are cut in a half-circle and attached (Fig.3.b). Rainwater will flow down through the lower half of the circle of bamboo facing upwards. On the last one, ijuk is reposed on the roof of the building with a thickness of $2 \mathrm{~cm}$ and arranged very tightly to avoid leakage. The ijuk is installed vertically overlapped to facilitate rainwater evacuation and maintenance processes (Figure 3c).

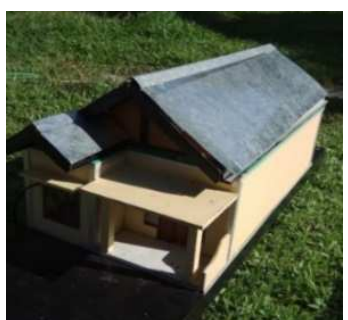

a.
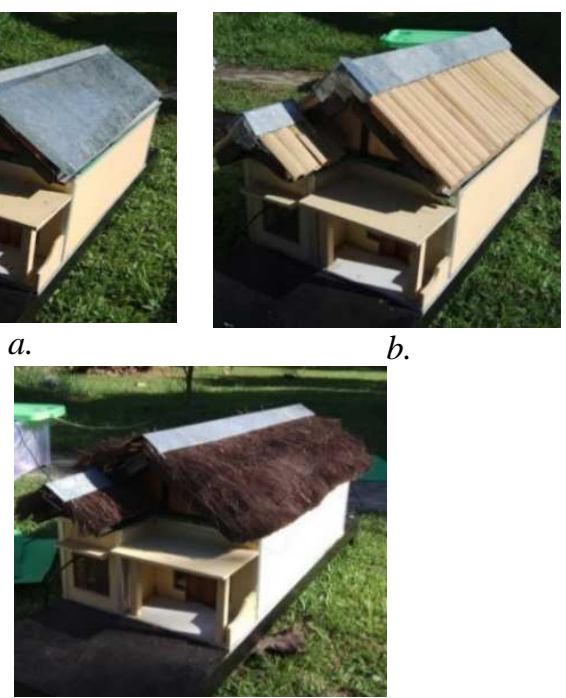

$b$.

Fig. 3 Three building prototypes with different roofing materials: (a) Zinc-plate, (b) Bamboo, and (c) Ijuk

\section{The Protocol of Experiment and Instrumentation}

In each building, four temperature sensors are installed on (1) the outer surface of the roof, (2) the attic zone (3) the bed room-1, and (4) the living room. Room air temperature measurement is using a digital thermocouple sensor $D S$ -
$18 B 20$, which can measure up to $125^{\circ} \mathrm{C}$ with an accuracy of $\pm 0.5{ }^{\circ} \mathrm{C}$. Measurement data is stored in a 20 - channel data logger IOT-Monitoring V1.0 developed by the Energy Conversion Laboratory of the Mechanical Engineering Department, Universitas Negeri Padang (UNP). The temperature is measured and logged every thirty-minute intervals over three days on 28-31 May 2019. Temperature measurements of prototype buildings are performed in an open location without any shadow from other surrounding objects. Temperature measurements in this study have been carried out in the Mechanical Engineering Department, Universitas Negeri Padang (Figure 4b).

\section{Thermal Comfort Indicators}

Thermal comfort is an important requirement in the design of sustainable buildings. A comfortable temperature in the building will ensure occupant health and productivity. In this study, the thermal comfort of the room will be evaluated in more detail using the Degree Hour thermal discomfort indicator $(D H)$ and discomfort rate $(D R)$. Based on the definition of ISO EN-15251, 2007 [27], Degree Hours thermal discomfort (in ${ }^{0} \mathrm{Ch}$ ) is the sum of the excess temperature that exceeds the limit of comfort temperature during the measurement period and is calculated by Equation 1.

$$
D H=\sum_{i=1}^{i=144} T_{i}-T_{\text {Comf }}
$$

where $T_{i}\left({ }^{0} \mathrm{C}\right)$ is the indoor temperature at time- $i, T_{\text {Comf }}$ is a comfortable temperature limit $\left(27{ }^{0} \mathrm{C}\right), i$ is the number of temperature measurements in every 30 minutes time step. The value of Degree Hour can be converted into energy needs that should be used for the indoor cooling system so the building can be completely comfortable.

Another indicator, Thermal Discomfort Rate (DR in \%) is a percentage of time with temperatures above the comfort limit compared to the total time in three days of measurement and calculated by Equation 2 [16].

$$
D R=\frac{h_{\text {comf }}}{h_{\text {total }}}
$$

where $h_{\text {conf }}$ is the amount of measurement time in which indoor temperature is within the comfort limit, and $h_{\text {total }}$ is the total measurement time.

\section{RESULTS AND DISCUSSION}

The temperature measurement data is analyzed to evaluate the thermal effect of roof material on building temperature and thermal comfort. By comparing the thermal effect of different roof materials, several parameters will be discussed here, including; the changes in roof temperature, indoor thermal comfort level, free cooling potential and risk of overheating, and evaluation of building thermal inertia. In addition, for more detailed data analysis, the profile of outdoor temperature in the measurement site needs to be presented first.

\section{A. Outdoor Air Temperature Profiles on Sites}

Padang is in the equatorial region with a humid tropical climate and has relatively high air temperatures and humidity (Fig.4). The average temperature at this location for three days of experiments was at $27,1{ }^{0} \mathrm{C}$. The lowest 
temperature at night fell to $23.9{ }^{\circ} \mathrm{C}$ at $06.00 \mathrm{am}$, and the highest temperature at noon occurred around 12:30 pm, reached $30.7{ }^{0} \mathrm{C}$. The temperature amplitude between day and night was $6.8{ }^{0} \mathrm{C}$. Located in a coastal area with high humidity, clouds containing water vapor often cover the sky of Padang. The clouds during the day can prevent direct radiation from sunlight, which can reduce the air temperature around the site in a few moments. This can be identified from the significant decrease in roof surface temperature at certain times when the sky is covered by clouds (see Fig.5).

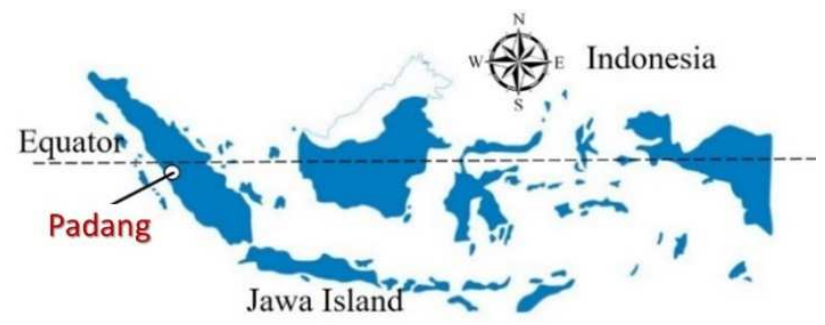

a.

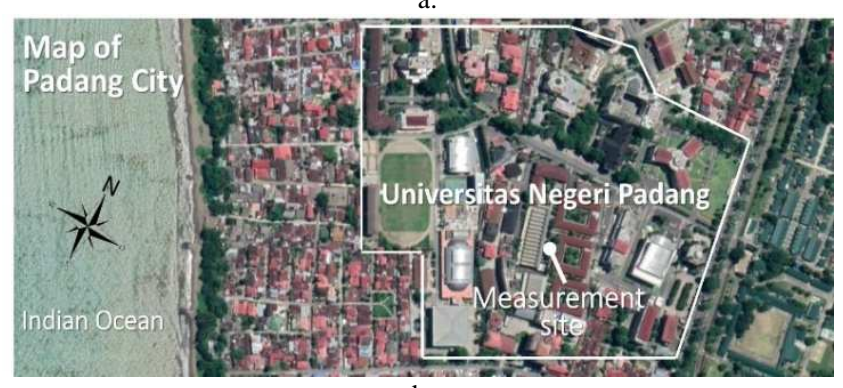

b.

Fig. 4 Measurement site; (a) UNP's campus in the map, (b) temperature measurement site in UNP

\section{B. Changes in Roof Temperature}

The roof is an element of the building envelope directly exposed to changes in outdoor climate parameters such as solar radiation, wind, rain, etc. Since the roof has high zenith angles and faces directly toward the sun, the solar heat on the roofs' surface is higher than the walls. Direct solar radiation that hits the surface of the roof will be reflected in part into the atmosphere and absorbed the other part, which will then affect the surface temperature of the roof. The amount of solar radiation's absorption and reflection depends on the thermal properties of the roof. Figure 5 shows the roof surface temperature profile for all types of material.

TABLE II

THE TEMPERATURE PROFILE OF THE OUTER SURFACE OF THE ROOF

\begin{tabular}{|c|c|c|c|}
\hline Temperature $\left[{ }^{\mathbf{0}} \mathbf{C}\right]$ & Zinc plate & Bamboo & Plam fiber \\
\hline$T_{\text {Roof }}$, minimum & 23.6 & 23.8 & 23.6 \\
\hline$T_{\text {Roof }}$, maximum & 59.0 & 49.9 & 56.5 \\
\hline$T_{\text {Attic }}$, minimum & 43.5 & 40.8 & 40.4 \\
\hline
\end{tabular}

Figure 5 indicates that the highest surface temperature occurs on a roof with zinc material $\left(T_{\text {Roof- }-1}\right)$. During the day, the outer surface of the zinc roof can reach temperatures of up to $59{ }^{\circ} \mathrm{C}$. The high temperature on the surface of the zinc roof occurred because of the large fraction of heat absorbed on the surface. Besides, zinc is a very good thermal conductor. The sun's heat is absorbed on the surface and immediately transferred by conduction to the interior, which has a lower temperature. It will increase the temperature in the attic zone. The temperature in the attic zone for the zinc plate roof was the hottest $\left(43.5{ }^{0} \mathrm{C}\right)$ among the other two types of roof $\left(40.8{ }^{0} \mathrm{C}\right.$ for the bamboo roof and $40.4{ }^{\circ} \mathrm{C}$ for ijuk roof) as shown in Table II and Figure 5. The high temperature in the attic zone will potentially raise the temperature of the room below if it is not evacuated optimally.

The roof with bamboo material has the lowest surface temperature $\left(49.9{ }^{0} \mathrm{C}\right.$ ) among the other types of roof (see Table II). With a brighter color, bamboo reflects a large amount of direct solar radiation to the atmosphere. Besides, bamboo is a thermal resistor so that the heat transfer by conduction to the attic zone is smaller than the zinc plate material from Table II, the maximum temperature observed in the attic zone during the day for the second case (bamboo roof) was $2.65{ }^{0} \mathrm{C}$ lower than the first case (zinc plate roof).

The outer surface of the Ijuk roofs has a temperature that is almost as high as zinc roofs. Ijuks have a dark color with a lower Albedo coefficient compared to bamboo. Having a low reflection coefficient, it absorbed most of the heat hitting the surface of the material. Unlike zinc, ijuk is not a good conductor of heat. The heat absorbed on the surface is not fully transferred to the attic zone through conduction. The attic zone temperature on the ijuk roof is lower than the zinc roof (Fig.5). It shows that the conduction value on the ijuk roof is smaller than the zinc plate of the roof. The temperature measurements show that two natural materials, bamboo, and ijuk, have a thermal resistor to withstand the rate of heat transfer into the room, especially during the day. However, the room covered by thermal resistor material is at risk of overheating at night because of the low heat evacuation to an environment where the temperature is much lower.

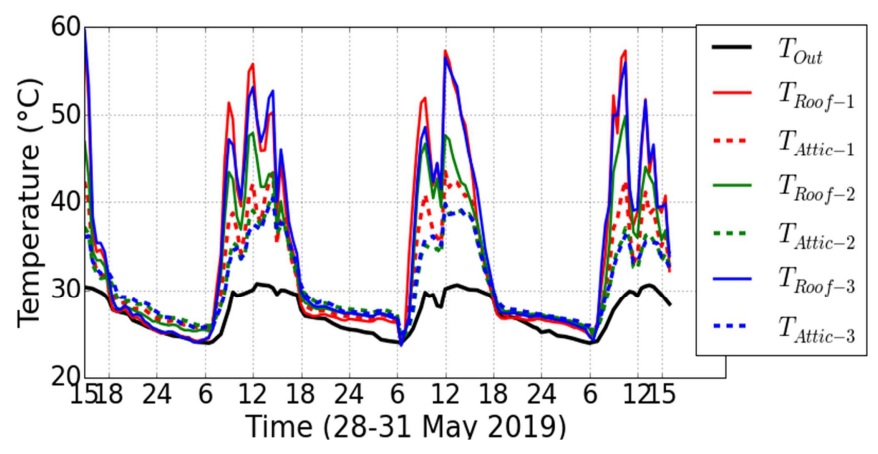

Fig. 5 The outer surface temperature of the roof with different materials ( $T_{\text {Roof }}$ is roof's temperature, $T_{\text {Attic }}$ is the temperature of attic zone, subscript indices ${ }_{1,2}$ and 3 representing case- 1 , case- 2 and cas- 3 , respectively)

\section{Evaluation of Indoor Comfort Level}

The level of thermal comfort is a crucial factor to be considered in the selection of building envelope material. Usually, measurements of the thermal comfort are carried out in the areas occupied by the residents. In this case, two significant zones to be considered are Bed Room-1 (BR-l) and Living Room $(L R)$. The $B R-1$ is at the front and has a large window, while the LR is a quite large space connected to the kitchen at the back of the building. 
The results of temperature measurements on BR-1 and LR for three different types of roofing material are presented in Fig.6. In line with the previous results, the highest room temperature during the day occurs in buildings with zinc plate roofs. It shows that the thermal gain absorbed from solar radiation through the roof is a significant factor causing discomfort in the case of a free-floating temperature room. During the daytime period ( 6 am to $6 \mathrm{pm}$ ), air temperatures in BR-1 and LR in zinc roof houses can reach a maximum of $39.7{ }^{\circ} \mathrm{C}$ and $37.5{ }^{0} \mathrm{C}$ with an average temperature for three days of $30.3{ }^{\circ} \mathrm{C}$ and $29.8{ }^{\circ} \mathrm{C}$, respectively. With this condition, thermal comfort in the room during the day is always considered uncomfortable. It can be noticed in Figure 6 that the air temperature in the Living Room most of the time is beyond the comfort temperature limit $\left(27{ }^{\circ} \mathrm{C}\right)$ [28]. For the night period ( $6 \mathrm{pm}-6 \mathrm{am})$ as the occupation period for residential houses, the room conditions become more comfortable with an average indoor temperature not exceeding $28.0{ }^{\circ} \mathrm{C}$.

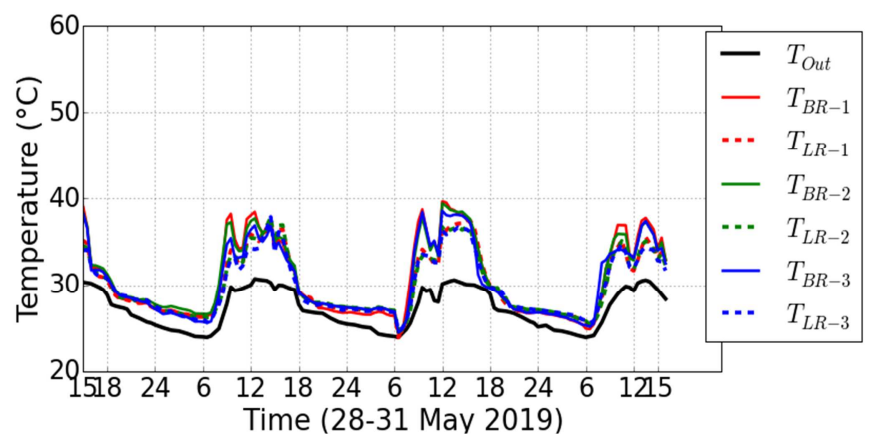

Fig. 6 The outer surface temperature of the roof with different materials. ( $T_{B R}$ is the temperature of the Bed room, $T_{L R}$ is the temperature of the living room, subscript indices 1,2 and 3 representing case-1, case- 2 and cas- 3 , respectively)

For the buildings with a roof using local natural materials, bamboo, and ijuk, the temperature of the rooms is observed lower than the zinc roof during the day. It shows that the nature of the insulator on bamboo and palm fiber can reduce the thermal gain of solar radiation obtained on the surface of the roof. The lowest temperature of rooms observed in the daytime is on building with ijuk roof (Fig.6). The maximum temperature in BR-1 for the case of ijuk roof is about $38.6{ }^{\circ} \mathrm{C}$ $\left(0.86{ }^{0} \mathrm{C}\right.$ lower than the bamboo roof and $1.07{ }^{0} \mathrm{C}$ lower than the zinc roof). This reduction of indoor air temperature significantly impacts energy consumption for air conditioning systems.

TABLE III

DEGREE HOUR DISCOMFORT AND DISCOMFORT RATE IN THE ROOM WITH DIFFERENT ROOF

\begin{tabular}{|l|l|c|c|}
\hline Roof material & Room & DH $(\mathbf{}$ Ch) & DR (\%) \\
\hline \multirow{2}{*}{ Zinc plated } & Bedroom-1 & 576.8 & 68.3 \\
\cline { 2 - 4 } & Living room & 480.2 & 75.2 \\
\hline \multirow{2}{*}{ Bamboo } & Bedroom-1 & 564.3 & 86.2 \\
\cline { 2 - 4 } & Living room & 472.6 & 78 \\
\hline \multirow{2}{*}{ Sugar palm fibre } & Bedroom-1 & 536.6 & 76.5 \\
\cline { 2 - 4 } & Living room & 452.4 & 78 \\
\hline
\end{tabular}

( $D H$ is Degree Hour thermal discomfort; $D R$ is Discomfort Rate)
From Table III, the highest degree hours discomfort for the two rooms measured is in the zinc plate roof building, and the lowest one is in the building with ijuk roofs. On the contrary, the discomfort rate in the zinc roof building is lower than the other two types of roofs. Low discomfort rate in buildings with zinc roof occurs because of the zinc roof evacuates a more tremendous heat to the environment than other materials by the time changing, from day to night until midnight. It is proved by the data in Figure 6, that the temperature of the room under the zinc roof is slightly lower than the other two buildings. In comparison, the ijuk roof shows good thermal performance during the day as well as during the night.

\section{Free Cooling Potential and Risk of Overheating}

As a building with a free-floating temperature, the indoor temperature is greatly affected by the heat of solar radiation and outside air temperature. In the free-floating temperature, the changes in outdoor conditions will immediately affect the indoor thermal condition. Figure 6 presents the profile of temperature in Bed Room -1 (BR-1) and Living Room (LR) in the three observed buildings for two periods; the diurnal period ( $6 \mathrm{am}-6 \mathrm{pm})$, and the nocturnal period ( $6 \mathrm{pm}-6 \mathrm{am})$. From the graph, it can be observed that there is free cooling potential to cool the indoor temperature through natural ventilation. During the daytime, there is a difference in indoor-outdoor temperature between $3.9{ }^{0} \mathrm{C}$ to $5.7{ }^{0} \mathrm{C}$. At night, the indoor-outdoor temperature difference is between $1.5{ }^{\circ} \mathrm{C}$ and $2{ }^{\circ} \mathrm{C}$. Despite the small influence, the difference in temperature is beneficial to cool the room through ventilation passively. Natural ventilation both day and night time by opening the window could reduce indoor air temperature due to cooler outdoor air. The higher the indooroutdoor air temperature difference, the higher the potential cooling benefit for building thermal comfort. With a high indoor-outdoor temperature difference, the excess heat in the room will be quickly evacuated to the outdoor by conduction heat transfer through the building envelope and by convection through infiltration. The indoor-outdoor air temperature differences for Bed Room-1 ( $\left.T_{\text {Outdoor }}-T_{B R-1}\right)$ and Living Room $\left(T_{\text {Outdoor }}-T_{L R}\right)$ in the three-building prototypes are presented in Table IV.

TABLE IV

INDOOR-OUTDOOR TEMPERATURE DIFFERENCE AS FREE COOLING POTENTIAL

\begin{tabular}{|l|l|c|c|}
\hline Material & Room & Diurnal $\left({ }^{\mathbf{}} \mathbf{C}\right)$ & Nocturnal $\left({ }^{\mathbf{0}} \mathbf{)}\right.$ \\
\hline Zinc plate & Bed room-1 & 5.5 & 1.9 \\
\hline & Living room & 5.7 & 2.0 \\
\hline Bamboo & Bed room-1 & 5.5 & 1.5 \\
\hline & Living room & 5.5 & 1.9 \\
\hline Ijuk & Bed room-1 & 5.2 & 1.7 \\
\hline & Living room & 3.9 & 1.8 \\
\hline
\end{tabular}

Utilization of natural ventilation both day and night has considerable potential in reducing the room temperature. The difference in indoor-outdoor temperatures, as presented in Table IV, opening windows during the day can maximize the evacuation of excess heat to the environment and reduce overheating in the room significantly. However, thermal 
comfort in the room during the day still cannot be achieved. It happened because the outdoor air temperature during the day remains above the comfort temperature limit. Besides, the outdoor air temperature at night is quite low, ranging from $23.9{ }^{\circ} \mathrm{C}$ to $28.8{ }^{0} \mathrm{C}$. The low temperature of the outside air at night can be a cold reservoir for excessive heat discharges from the room to reduce the temperature of the building. However, the difference in indoor-outdoor nighttime temperatures is not too significant, that the potential for free cooling at night is not as high as during the day. Natural ventilation by opening the windows remains an alternative solution in maintaining thermal comfort at night as the active occupation period in the building. Although nocturnal natural ventilation has a significant potential for free cooling, there are some inconveniences of opening the window at night: insecure, raindrops splash, strong wind blow, etc.

\section{E. Evaluation of Building Thermal Inertia}

In general, building thermal inertia is obtained from building envelope materials such as walls, roofs, floors, etc. Buildings with high thermal inertia have considerable resistance to change in outside air temperature. The heat gain absorbed on the surface will be stored in the material so that there is a time-shifting temperature response in indoor air. In the case of a free-floating building, the thermal inertia of the building is very influential on the temperature profile of the room.

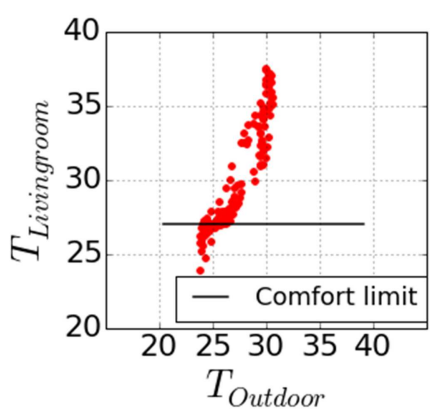

a.

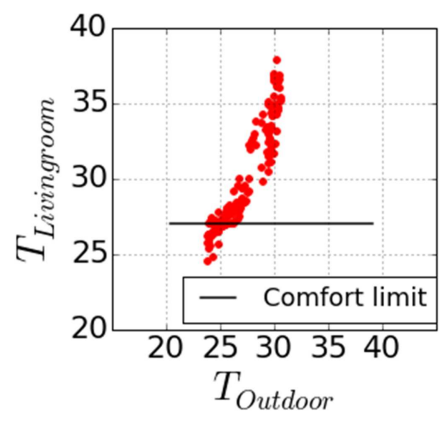

b.

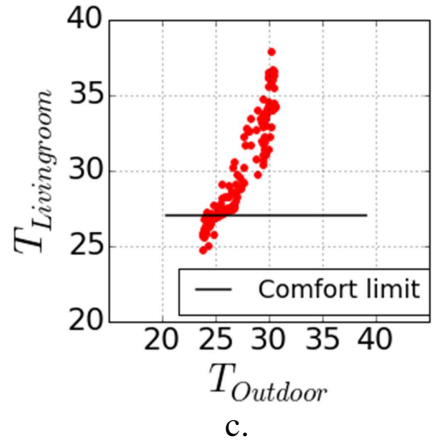

c.

Fig. 7 Changes in Living Room air temperature to outdoor air temperature variation for different roof material: a. zinc plate roof, b. bamboo roof and c. ijuk roof

Figure 7 shows the changes in Living Room temperature to outside air temperature. From the graphs in Figure 7, it is obvious that the thermal inertia value of the three buildings is almost similar. The increase in the room temperature as the changes in outside air temperature is quite high, particularly during the daytime when the outside air temperature is higher than $27^{\circ} \mathrm{C}$ (Fig.7). Changes in roofing material do not have a significant effect on the thermal inertia value of the building.

\section{CONCLUSION}

Experimental studies on the analysis of roofing material effect on indoor thermal comfort of a residential building in the tropical-humid climate region have shown an interest in using some local materials as alternatives for manufacturing building roofs. The zinc plate roof, which has often been used by people in tropical areas, shows a lower performance as a solar heat barrier, which has the potential to cause overheating during the day. On the other hand, two local materials often found in the Indonesian region, bamboo and $i j u k$ can be an alternative roofing material that works well in holding the rate of penetration of the solar heat to the inhabited room. The results of the experiment confirm that between the two alternative materials, ijuk roofs are better in increasing comfort during the day and evacuating an adequate amount of heat at night. However, it should be noted that the choice of roofing material must be complemented by a cost analysis and installation process as well as the availability of raw materials around the site. The results of the research highlighted in this paper are very useful for the improvement of bioclimate home design in Indonesia. The outlook of this research is to integrate the process of free cooling through natural ventilation to increase room comfort.

\section{ACKNOWLEDGMENT}

The authors wish to thank Universitas Negeri Padang and the Ministry of Education and Culture of the Republic of Indonesia for their financial support, and Laboratoire des Sciences de l'Ingénieur pour l'Environnement (LaSIE) the University of La Rochelle-France for their technical support.

\section{REFERENCES}

[1] I. Mujan, A. S. Anldjelković, V. Munćan, M. Kljajić, and D. Ružić, 'Influence of indoor environmental quality on human health and productivity-A review', Journal of cleaner production, vol. 217, pp. 646-657, 2019.

[2] Y. Geng, W. Ji, B. Lin, and Y. Zhu, 'The impact of thermal environment on occupant IEQ perception and productivity', Building and Environment, vol. 121, pp. 158-167, Aug. 2017, doi: 10.1016/j.buildenv.2017. 05.022.

[3] M. Fountain and E. A. Arens, 'Air movement and thermal comfort', ASHRAE Journal, vol. 35, no. 8, 1993.

[4] H. Yan et al., 'The coupled effect of temperature, humidity, and air movement on human thermal response in hot-humid and hot-arid climates in summer in China', Building and Environment, p. 106898, 2020 .

[5] I. Sukarno, H. Matsumoto, and L. Susanti, 'Household lifestyle effect on residential electrical energy consumption in Indonesia: On-site measurement methods', Urban Climate, vol. 20, pp. 20-32, 2017, doi: 10.1016/j.uclim.2017.02.008.

[6] S. Mirrahimi, M. F. Mohamed, L. C. Haw, N. L. N. Ibrahim, W. F. M. Yusoff, and A. Aflaki, 'The effect of building envelope on the thermal comfort and energy saving for high-rise buildings in hothumid climate', Renewable and Sustainable Energy Reviews, vol. 53, pp. 1508-1519, 2016.

[7] E. Koumoulas, A. Rokkou, and M. Moschakis, 'Bioclimatic Design, Evaluation of Energy Behavior and Energy-Saving Interventions at the Theagenio Cancer Hospital', International Journal of Energy and Power Engineering, vol. 13, no. 3, pp. 114-122, 2019.

[8] P. K. Latha, Y. Darshana, and V. Venugopal, 'Role of building material in thermal comfort in tropical climates-A review', Journal of Building Engineering, vol. 3, pp. 104-113, 2015. 
[9] V. Bianco, A. Diana, O. Manca, and S. Nardini, 'Thermal behavior evaluation of ventilated roof under variable solar radiation', Int. J. Heat Techn, vol. 34, pp. S346-S350, 2016.

[10] R. Lapisa, A. Karudin, F. Rizal, Krismadinata, and Nasruddin, 'Passive cooling strategies in roof design to improve the residential building thermal performance in tropical region', Asian J Civ Eng, vol. 20, no. 4, pp. 571-580, Feb. 2019, doi: 10.1007/s42107-01900125-1.

[11] J. Lucero-Álvarez and I. R. Martín-Domínguez, 'Effects of solar reflectance and infrared emissivity of rooftops on the thermal comfort of single-family homes in Mexico', in Building Simulation, 2017, vol. 10, pp. 297-308.

[12] M. S. Al-Homoud, 'Performance characteristics and practical applications of common building thermal insulation materials', Building and environment, vol. 40, no. 3, pp. 353-366, 2005.

[13] F. Ghorbanalavi, 'Performance characteristics and practical applications of common building polymeric materials for building envelope', Journal of Energy and Economic Development, vol. 3, no. 2, pp. 13-33, 2018.

[14] E. Prianto and A. Dwiyanto, 'Concrete Roof Tile Cover Profile In Efficiency of Electric Energy Consumption on Residential Scale', Modul, vol. 13, no. 1, pp. 23-34, 2013.

[15] R. Lapisa, 'The Effect of Building Geometric Shape and Orientation on Its Energy Performance in Various Climate Regions', Int $J$ Geomate, vol. 16, no. 53, pp. 113-119, 2019.

[16] R. Lapisa, E. Bozonnet, M. O. Abadie, and P. Salagnac, 'Cool roof and ventilation efficiency as passive cooling strategies for commercial low-rise buildings - ground thermal inertia impact', Advances in Building Energy Research, vol. 7, no. 2, pp. 192-208, 2013, doi: 10.1080/17512549.2013.865559.

[17] R. Lapisa, E. Bozonnet, M. Abadie, P. Salagnac, and R. Perrin, 'Effect of ground thermal inertia on the energy balance of commercial low-rise buildings', presented at the BS2013, Chambéry, France, Aug. 2013.

[18] R. Lapisa, M. Abadie, E. Bozonnet, and P. Salagnac, 'Numerical analysis of thermal stratification modelling effect on comfort for the case of a commercial low-rise building', Hongkong, Jul. 2014.
[19] Z. Romani, R. Lapisa, A. Draoui, and F. Allard, 'Multicritera optimization on the energy-saving refurbishment of existing buildings to achieve low energy consumption by considering the climatic change', 2016, Accessed: Jan. 24, 2017. [Online]. Available: http://www.iaqvec2016.org/download/Files/1462.pdf.

[20] R. Lapisa, E. Bozonnet, P. Salagnac, and M. O. Abadie, 'Optimized design of low-rise commercial buildings under various climates Energy performance and passive cooling strategies', Building and Environment, vol. 132, pp. 83-95, Mar. 2018, doi: 10.1016/j.buildenv.2018.01.029.

[21] R. Lapisa et al., 'Effect of skylight-roof ratio on warehouse building energy balance and thermal-visual comfort in hot-humid climate area', Asian J Civ Eng, vol. 21, no. 5, pp. 915-923, Jul. 2020, doi: 10.1007/ s42107-020-00249-9.

[22] N. Laghmich, Z. Romani, R. Lapisa, and A. Draoui, 'The impact of internal gains on thermal stratification for public buildings', in IOP Conference Series: Materials Science and Engineering, 2019, vol. 609, no. 4, p. 042090.

[23] P. Sharma, K. Dhanwantri, and S. Mehta, 'Bamboo as a building material', International Journal of Civil Engineering Research, vol. 5, no. 3, pp. 249-254, 2014.

[24] A. Das and S. Sarkar, 'Importance of bamboo in building construction', Int J Res Eng Technol, vol. 5, no. 6, pp. 389-392, 2018.

[25] S. Alam and D. Baco, 'Development and Utilization of Palm Oil Plants in South Sulawesi', in Palm Sugar Plant Development. Aren National Seminar Prosiding. Tondano. Balai Penelitian Tanaman Kelapa dan Palma Lain, 2004, vol. 9, pp. 15-21.

[26] I. Munandar, 'Mechanical and Physical Properties of palm sugar Fibers (Arenga Pinnata Merr)', 2013.

[27] ISO EN-15251, 'Indoor environmental input parameters for design and assessment of energy performance of buildings addressing indoor air quality, thermal environment, lighting and acoustics'. International Organization for Standardization, 2007, [Online]. Available: https://www.iso.org/home.html.

[28] SNI 03-6197, 'Energy Conservation in the Air Conditioning System in Buildings'. Badan Standardi sasi Nasional, 2000. 